\title{
A STUDY OF THE HUMAN FOETAL RENAL PELVICALYCEAL PATTERNS
}

\author{
R. Rajad', Savithri Krishnan² \\ ${ }^{1}$ Assistant Professor, Department of Anatomy, Government T. D. Medical College, Alappuzha, Kerala. \\ 2 Professor, Department of Anatomy, Government Medical College, Parippally, Kollam, Kerala.
}

ABSTRACT
BACKGROUND
The renal pelvicalyceal system consists of the renal pelvis, major calyces and minor calyces. They present numerous patterns, which
can be grouped into three. The pattern in the foetus may change to other patterns in the adult. Knowledge of these patterns in the
foetus might be of use for the smooth execution of surgical procedures, since foetal surgery is emerging fast as a distinct specialty.

\section{MATERIALS AND METHODS}

50 human foetal kidneys of both sexes from the Department of Pathology, Government Medical College, Thiruvananthapuram, Kerala, were dissected to study the pelvicalyceal patterns.

\section{RESULTS}

Three major types of pelvicalyceal patterns - tricalyceal, bicalyceal and multicalyceal were observed. The surfaces of the foetal kidneys were lobulated and each lobule had minor calyces projecting into them. Tricalyceal pattern constituted $36 \%$, multicalyceal $34 \%$ and bicalyceal $24 \%$ in the foetal kidneys. But there is an increase in the tricalyceal pattern from $36 \%$ in the foetal kidneys to $54 \%$ in the adult kidneys. Similarly, there is also an increase in the bicalyceal pattern from $24 \%$ in the foetal to $30 \%$ in adult kidney.

\section{CONCLUSION}

The change in the pelvicalyceal pattern in foetus and in adult indicates that about $62 \%$ of the multicalyceal pattern in foetus matured mostly to tricalyceal pattern and some to bicalyceal pattern in the adult. The theory of multiple calyces in the foetus, fusing to form the adult pelvicalyceal system is further supported by the disappearance of foetal lobulations in the adult.

\section{KEYWORDS}

Foetal Kidney, Major Calyx, Minor Calyx, Pelvicalyceal System, Renal Pelvis, Lobulations.

HOW TO CITE THIS ARTICLE: Rajad R, Krishnan S. A study of the human foetal renal pelvicalyceal patterns. J. Evolution Med. Dent. Sci. 2016;5(97):7116-7119, DOI: 10.14260/Jemds/2016/1611

\section{BACKGROUND}

The proximal parts of the urinary tract, which lies within the renal sinus constitutes the renal pelvicalyceal system. It serves as a conduit for the transport of urine from the kidney through the ureter to the bladder. ${ }^{1}$ The minor calyces numbering from 8 - 18 may be loosely grouped into those draining the upper and lower poles and two parallel rows of anterior and posterior calyces draining the middle portion of the kidney. The minor calyces consist of a funnel portion encompassing the papillae and a neck of varying length known as the infundibulum. The coalescence of these calyces form a large chamber called a major calyx, which generally numbers two to three. The major calyces drain into the renal pelvis. ${ }^{2}$

Graves $^{3}$ in 1986 and Sampaio ${ }^{4}$ in 1990 classified the pelvicalyceal patterns into different types. The present study followed the simple and recent classification of Ningthoujam $\mathrm{DD}^{5}$ (2005). His classification included all the subtypes of the previous two classifications. He classified the renal pelvicalyceal system into three groups. These three groups are

Financial or Other, Competing Interest: None.

Submission 28-10-2016, Peer Review 21-11-2016,

Acceptance 28-11-2016, Published 05-12-2016.

Corresponding Author:

Dr. R. Rajad,

Assistant Professor,

Department of Anatomy,

Government T. D. Medical College,

Alappuzha, Kerala.

E-mail:r.rajad@gmail.com

DOI: $10.14260 /$ jemds $/ 2016 / 1611$ bicalyceal (Y shaped), tricalyceal (Triangular) and multicalyceal (radiate).

Sykes $^{6}$ in a thorough study made with casts of human kidneys showed that in the human foetus, cleft formation leads to lobulations of the kidney. In the foetus, the 14 minor calyces which are present in the 30th week correspond exactly to the 14 foetal lobules, later their number diminishes. He demonstrated that most often there is persistence of three upper lobe, three hilar lobe and two to three lower lobe calyces. He concluded that the foetal calyces follow a constant pattern of development and that the adult calyceal variation can be traced to their stage of development. Later, Hodson ${ }^{7}$ studied the foetal lobar structure of kidney and found that only two lobes are seen in the 10-week old foetuses. The number of lobes increases as weeks progress and are separated by interlobar septa of Bertin, which are indicated by grooves of foetal lobulations on the surface.

The objective of the present study was to find out the different patterns of pelvicalyceal system and the lobulations in foetal kidneys and to compare this data with previous studies on adult pelvicalyceal pattern.

\section{MATERIALS AND METHODS}

A cross-sectional study of 50 human cadaveric foetal kidneys of both sexes from the Department of Pathology, Government Medical College, Thiruvananthapuram, Kerala was conducted. The gestational age was calculated from the menstrual history obtained from the records. The youngest foetus studied was of 7 weeks gestation and the oldest that of full-term foetus. The dissected kidneys were inspected for surface lobulations and 
then cut coronally in a plane anterior to the renal pelvis from the lateral convex border. The major and minor calyces were observed to study the pelvicalyceal system. They were grouped into multicalyceal, bicalyceal and tricalyceal patterns and photographs were taken. Consecutive intact kidneys of both sides were included. Macerated foetuses and those with renal anomalies were excluded.

\section{RESULTS}

\section{Surface Lobulations}

At 10 weeks, the surface is smooth and no lobules were seen. At 14 weeks of gestation, faint lines were seen indicating the appearance of lobules. At 20 - 24 weeks of intrauterine life the surface showed typical surface lobulations, the number of which increased with age. After 32 - 34 weeks of intrauterine life, they became less prominent. The pattern was variable. The lobulations had different shapes like large triangular Fig. IA) and rectangular (Fig. IB).

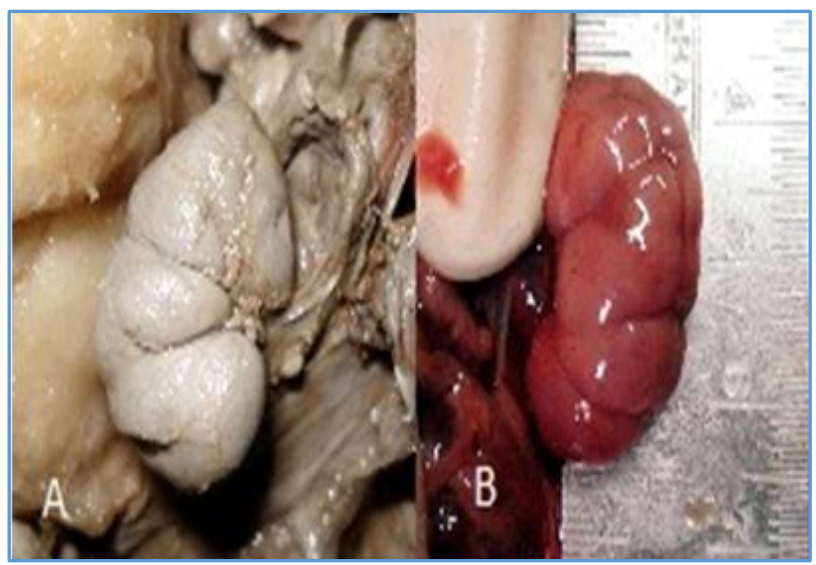

Figure I. Patterns in Surface Lobulations of Foetal Kidneys. A. Large Triangular, B. Rectangular

The surface of the kidneys also showed large round or polygonal lobules. Small and numerous irregular lobules looking like a mulberry were also observed (Fig. II).

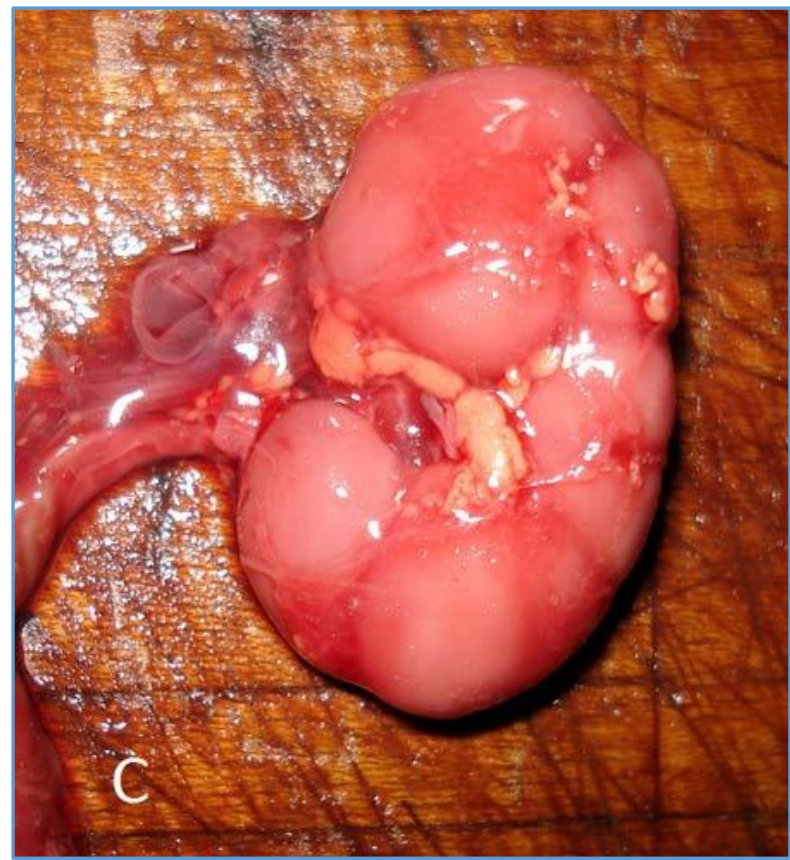

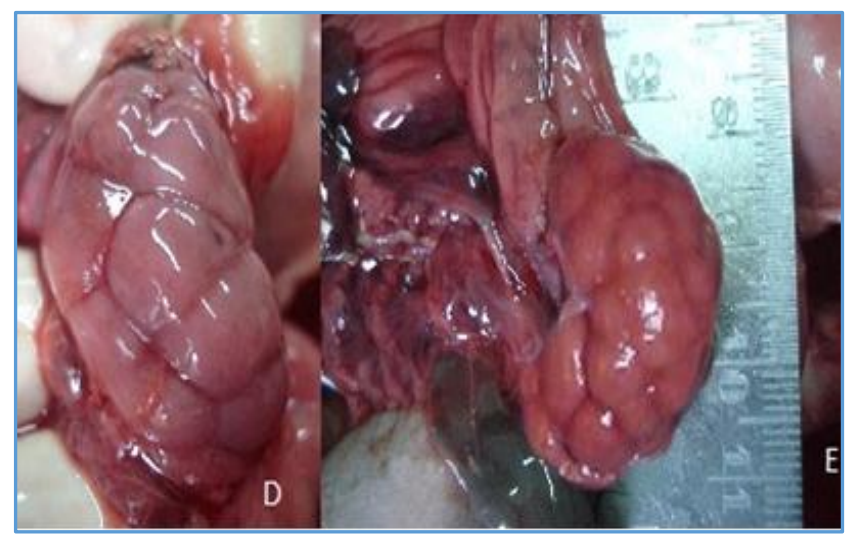

\section{Figure II. Patterns in Surface Lobulations of Foetal Kidneys. C. Large Round, D. Large Polygonal, E. Small Round - Mulberry Type}

Coronal section revealed that each lobe has a central calyx, which receives a pyramid. The lobes were separated by interlobar septa of Bertin, indicated by the grooves on the surface. These lobulations contained minor calyces projecting into them.

\section{Renal Pelvicalyceal Patterns}

The renal pelvicalyceal patterns were the triangular or tricalyceal pattern, radiate or multicalyceal pattern and $\mathrm{Y}$ shaped or bicalyceal pattern and some unusual forms.

The percentage in foetal pelvicalyceal patterns observed in the present study is depicted in Table I.

\begin{tabular}{|c|c|c|}
\hline Pelvicalyceal Pattern & Numbers & Percentage \\
\hline Tricalyceal & 18 & 36 \\
\hline Multicalyceal & 17 & 34 \\
\hline Bicalyceal & 12 & 24 \\
\hline Others & 03 & 06 \\
\hline
\end{tabular}

a) The triangular type or tricalyceal type (Fig. III-A) was seen in 36\% (18 kidneys). The infundibulum is longer and resembles the stalk of a cauliflower. Pelvis space is moderate in size. Three major calyces - superior, middle and inferior formed by the fusion of respective minor calyces open into it. This was the commonest type of renal pelvis. The position of the middle calyx was variable, sometimes located close to the upper calyx. The three calyces are usually of the same size.

b) The multicalyceal or radiate type (Fig. III-B) was seen in $34 \%$ (17 kidneys). The pelvis was the biggest in this category characterised by the presence of upper and lower major calyces. Three or more minor calyces drained independently into the pelvis between the two major calyces. In this category, no distinct anterior and posterior division of the middle calyces are seen. Infundibulum of the minor calyces is so short that they seem to open directly into the pelvis. 


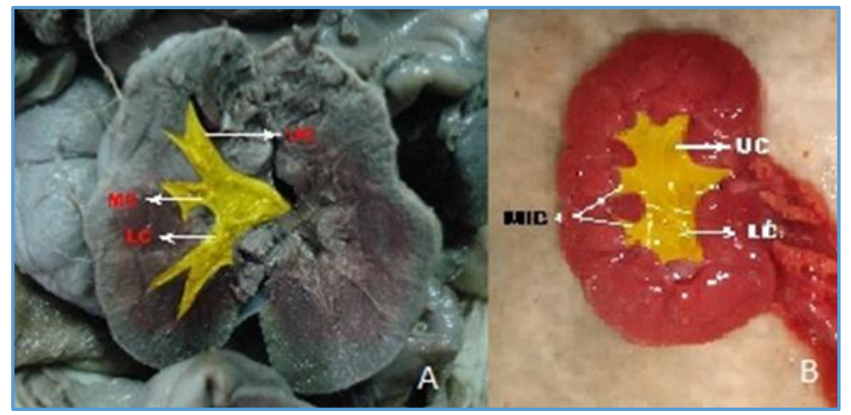

Figure III A \& B. The Triangular and Multicalyceal Types of Foetal Pelvicalyceal Patterns

(UC = Upper Calyx, MC = Middle Calyx, LC = Lower Calyx, MiC $=$ Minor Calyx, $U=$ Ureter)

c) Y shaped pelvis or bicalyceal pattern (Fig. IV-C) formed $24 \%$ (12 kidneys). The pelvic capacity is less with long calyceal infundibulum. The pelvis is formed by the convergence of two major calyces, the upper (superior) and lower (inferior) which may or may not be symmetrical and the middle calyx is absent. This pattern can be subclassified into symmetrical and asymmetrical.

d) In 3 cases (6\%), there was no major calyx. Instead, the minor calyces opened directly into the pelvis (Fig. IV-D).

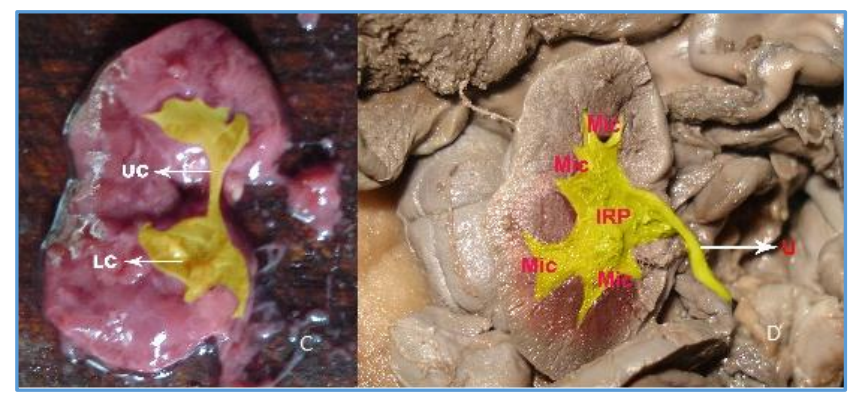

Figure IV C \& D. The Bicalyceal and a Special Type of Foetal Pelvicalyceal Pattern (UC = Upper Calyx, MC = Middle Calyx, LC = Lower Calyx, MiC = Minor Calyx, $U=$ Ureter, $I R P$ = Intra-renal pelvis)

\section{DISCUSSION}

\section{Lobulations of the Kidney}

The present study showed the indication of the first lobulation at 14 weeks of gestation, definite lobulations at 20 - 24 weeks. A steady increase in lobulations with age of the foetus followed by a decrease and less prominence after 32 - 34 weeks of gestation was also noted. This conforms to the studies of Ningthoujam, ${ }^{5}$ Sykes ${ }^{6}$ and Gasser. ${ }^{8}$ Sykes 6 described only two types of patterns of lobulations in the surface of the kidney, but the present study showed about five different patterns in lobulations.

\section{Pattern of the Major Calyces}

In the present study the findings in the tricalyceal, bicalyceal and multicalyceal pattern were $36 \%, 24 \%$ and $34 \%$ respectively in the foetal kidneys. This agrees with the findings of Ningthoujam. ${ }^{5}$ Fine and Keen ${ }^{9}$ have reported bicalyceal pattern to be the commonest. But the present study showed an increase in tricalyceal pattern.
Comparison of the Foetal Pelvicalyceal Pattern with that of the Adult

Purvi Mishra ${ }^{10}$ in the studies on the pelvicalyceal patterns in adult kidneys reported that tricalyceal pattern constituted $54 \%$, bicalyceal $30 \%$ and multicalyceal $12 \%$ respectively. Studies by Wadekar ${ }^{11}$ in 100 cadaveric adult kidneys and Ningthoujam 5 in 100 adult Intravenous Pyelograms also showed similar results.

On comparing the data collected on foetuses in this study with the above reported findings, it is clear that there is an increase in the tricalyceal pattern from $36 \%$ in the foetal kidneys to $54 \%$ in the adult kidneys. Similarly, there is an increase in the bicalyceal pattern from $24 \%$ in the foetal to $30 \%$ in adult kidney. This change indicates that about $62 \%$ of the multicalyceal pattern matured into mostly tricalyceal pattern and some into bicalyceal pattern in the adult. The multicalyceal pattern formed $34 \%$ in the foetal kidneys and only $12 \%$ in the adult.

The comparison of the pelvicalyceal patterns in foetuses in the present study with the adult pelvicalyceal patterns as described by Purvi Mishra ${ }^{10}$ is shown in Table II.

\begin{tabular}{|c|c|c|}
\hline $\begin{array}{c}\text { Type of } \\
\text { Pelvicalyceal } \\
\text { Pattern }\end{array}$ & $\begin{array}{l}\text { Percentage in } \\
\text { Foetal Kidneys } \\
\text { (Present Study) }\end{array}$ & $\begin{array}{c}\text { Percentage in } \\
\text { Adult Kidneys } \\
\text { (Purvi Mishra - } \\
\text { 2015) } \\
\end{array}$ \\
\hline Tricalyceal & 36 & 54 \\
\hline Multicalyceal & 34 & 12 \\
\hline Bicalyceal & 24 & 30 \\
\hline Others & 04 & 04 \\
\hline \multicolumn{3}{|c|}{$\begin{array}{c}\text { Table II. Comparison of the Foetal Pelvicalyceal Pattern } \\
\text { with that of the Adult }\end{array}$} \\
\hline
\end{tabular}

\section{CONCLUSION}

The multicalyceal pattern of pelvicalyceal system constituted a significant percentage in the foetal kidneys. But, however, it formed only a minor in the adult, as mentioned in early studies. This decrease in the multicalyceal pattern was made up by an increased proportion of tricalyceal and bicalyceal patterns as against the foetal kidneys. These findings support the theory of merging of minor calyces in a massive fashion in the upper major calyces. A significant percentage of multicalyceal pattern in the foetus matured into tricalyceal pattern and some into bicalyceal pattern in the adult. This theory of multiple calyces in the foetus fusing to form the adult pelvicalyceal system is further supported by the disappearance of foetal lobulations in the adult.

Knowledge of such wide ranging pattern of pelvicalyceal system would serve to help the surgeons to plan and execute their prenatal, intrauterine procedures correctly.

\section{REFERENCES}

1. McMinn RMH. Kidneys, ureters and suprarenal glands. In: Last's anatomy. $8^{\text {th }}$ edn. Churchill Livingston 1990:369-70.

2. Dyson M. Churchill livingston edinburgh. In: Gray's anatomy. 38th edn. Urinary system 1995:1813-45.

3. Graves FT. The anatomy of intra renal arteries and its application in segmental resection of kidney. British Journal of surgery 1986:132-9.

4. Sampaio FJ, Aragio AH. Anatomical relation between the intrarenal arteries and kidney collecting system. Journal of Urology 1990;143(4):679-81. 
5. Ningthoujam DD, Chongtham RD, Sinam SS. Pelvi-Caliceal system in foetal and adult human kidneys. Journal of anatomical society of India 2005;54(1):1-11.

6. Sykes D. The arterial supply of human kidney with special reference to accessory renal arteries. British journal of surgery 1963;50(222):368-74.

7. Hodson J. The lobar structure of the kidney. British journal of urology 1972;44(2):246-61.

8. Gasser B, Mauss Y, Ghnassia JP, et al. A quantitative study of normal nephrogenesis in human fetus: its implication in the natural history of kidney changes due to low obstructive uropathies. Foetal Diagn Ther 1993;8(6): 371-84
9. Fine $H$, Keen EN. The arteries of the human kidney. Journal of anatomy 1966;100(4):881-94.

10. Mishra P, Onkar D, Ksheersagar DD, et al. The study of pelvicalyceal system in adult human kidney. J Cont Med A Dent 2015;3(2):12-6.

11. Wadekar PR, Gangane SD. Study of variations in the pelvicalyceal system of kidney and its clinical importance. Journal of College of Medical Sciences-Nepal 2012;8(3): 17-21. 